\title{
Adoption of online proctored examinations by university students during COVID-19: Innovation diffusion study
}

\author{
Raghu Raman $^{1}$ (D) Sairam $B^{2} \cdot$ Veena $^{3} \cdot$ Hardik Vachharajani ${ }^{4}$. \\ Prema Nedungadi ${ }^{3}$
}

Received: 30 January 2021 / Accepted: 4 May 2021 / Published online: 31 May 2021

(C) The Author(s), under exclusive licence to Springer Science+Business Media, LLC, part of Springer Nature 2021

\begin{abstract}
COVID-19 global pandemic pushed a large number of higher educational institutions to use Online Proctored Exams (OPE) because of government-imposed lockdowns. Treating OPE as an educational technology innovation, we apply the diffusion of innovation theory in predicting factors affecting its adoption by university students which we believe is the first of its kind research study. The study presented here reviews OPE, its types, architecture, challenges, and prospects and then focuses on the student adoption experience at a large, multi-campus higher educational institution. We have used the fine-grained Aspect Level Sentiment Analysis to check the university students' attitudes towards the Online Proctored Exams. We then used linguistic features to extract the aspect terms present in the feedback comments which showed that $55 \%$ of university students having a positive attitude towards OPE. Results of our study show that innovation characteristics such as relative advantage, compatibility, ease of use, trialability, and observability were found to be positively related to acceptance of OPE.
\end{abstract}

Keywords Innovation · Diffusion · University students · Online exams · Covid-19

\section{Introduction}

\subsection{Online learning and examinations in universities}

From different educational narratives around the world, online learning has become the new norm. According to Sindre and Vegendla (2015), online learning allows for distance learning via the use of the internet, computer, and other related devices. UNESCO further asserted that since tertiary institutions (universities) provide a

Raghu Raman

raghu@amrita.edu

Extended author information available on the last page of the article 
training ground for the intellectual, social, and psychological development of learners, making online learning and assessment (examinations) available should not be overlooked. Manathunga (2005) added that online learning for students in tertiary institutions is a good way to promote research and scholarship. Online examinations have been considered to be effective in open learning processes in developed countries where there is a high level of sophisticated internet services and proctored functions (Mohammad, 2015; Sunar et al., 2015; Amigud et al., 2017). Kaiiali et al. (2016) added that e-learning is greatly used and appreciated in the global market for extraordinary development in recent times. In the same vein, the global industry market has an estimated budget of about USD 91 billion for the proper execution of e-learning.

Berkey and Halfond (2015) highlight that universities in countries like the United States of America, the United Kingdom, India, China, Saudi Arabia, and many more, have seized the opportunities embedded in online learning; however, several studies have noted that there are many challenges rooted in the online examination if not proctored (monitored). Online learning has allowed people from different countries to study in countries without being physically present. Learners can travel out of their countries virtually and relate with classmates whom they would not have met without online learning. It is good to note that premier examination bodies such as GRE (Graduate Record Examination, USA), GMAT (Graduate Management Admission Test, USA), TOEFL (Test of English as a Foreign Language, USA), AIMA MAT (All India Management Association Management Aptitude Test, India), NLAT (National Law Admission Test, India), and so on, have adopted OPE. In the study of Alessio et al. (2017), it was revealed that online examinations that are not proctored are not reliable. Therefore, the use of Online Proctored Examinations (OPE) is becoming widely used by distance learning programs in universities for assessment and evaluation.

\subsection{Online Proctored Examinations (OPE)}

Online Proctored Examinations (OPE) have been considered one of the foremost online proctoring options that share the features of a real examination hall with a proctor observing examinations remotely. According to Northcutt et al. (2016), some of the features of real examinations such as proctor intervention during an examination, the timing for examinations, different methods of questioning (multiple choices, open-ended questions, matching, theory, etc.) are applicable in OPE. Corrigan-Gibbs et al. (2015) found that though examination malpractices might be prevalent in open-book examinations, they could be reduced in an OPE if well executed. This points to the fact that there is more monitoring of students, which they might not be conscious of when writing OPE.

OPE allows students in universities not just to write their examinations from the comfort of their rooms but to also be monitored and supervised through internet measures against all forms of fraud that could be carried out by students (D'Souza and Siegfeldt (2017). OPE, therefore, gives room for effectiveness, efficiency, accuracy, and integrity in digital learning assessment. In the words of Kyriazos (2018a) 
and Kyriazos (2018b), assessment is the process of evaluating students and placing judgmental values on their performance and ability. It was further added that the techniques through which assessment is carried out go a long way in the reliability and validity of the assessment (Kotsou \& Leys, 2016). To this end, Dawson (2015) opined that OPE is best carried out through the use of monitoring software and online video images- hence, students' examinations are automatically proctored via their students' videos, images, and log-in details.

Some of the foremost universities around the world that practice OPE are Harvard University, University of California, Irvine, Georgia Institute of Technology, École Polytechnique, Michigan State University, California Institute of the Arts, Hong Kong University of Science and Technology, UCL (University College London), Massachusetts Institute of Technology (MIT) and many more (Siemens, 2015). These universities do not just provide their students with excellent platforms for online learning; they also provide their learners with the opportunities to write examinations from the comfort of their rooms and still be under supervision. It has also been found that most of the rules and regulations, as well as penalties/punishments attached to open-book examination, are also attached to OPE. Such penalties of examination malpractices as cancellation of examination, re-writing of examination, and expulsion are synonymous to the two categories of examinations (Manathunga, 2005; Sindre \& Vegendla, 2015; Hovde \& Olsen, 2015; Dawson, 2015).

\subsection{Types of Online Proctored Examinations (OPE)}

OPE has been categorized into two basic categories: automated proctoring and live proctoring. Nie et al. (2020) suggested that live proctoring is the better form of OPE as an examination is not just monitored remotely but the proctor can view the students through the screen. Live OPE has teachers/proctors assigned to the exam to view students and monitor examinations in real-time. The proctors check that the students assigned to them are present and approve the ones in class. As the proctors may not be familiar with each student, often the photo of the student holding the student ID is captured by the device camera and recorded. The proctors continue to monitor for any suspicious behavior and to make sure that an imposter does not replace the student during the exam.

Unlike an automated proctored exam, the examinee needs to wait for a scheduled time to write an examination. In the study by Kaiiali et al. (2016), it was found that the availability of students' mobile/tablet devices, strong Wi-Fi network, and access to the exam will contribute greatly to the reality of live exam proctoring. In some systems, the secure exam environment does not allow access to internet and local files but allows local applications such as Microsoft Excel Kaiiali et al. (2016).

According to Kubiatko (2020), automated proctoring allows an online examination to be written at the chosen time of the examinee and yet, be monitored while writing the examination. Automated proctoring is fast growing because it saves time, is highly scalable, aids individual examinee supervision, and gives reports of possible examination fraud or malpractices by the examinee. Hastap Report About Global Self-Paced E-Learning Market (2020) added that this efficacy in online 
examination supervision is achieved because any online examination whatsoever is written through the use of a mobile phone or a computer system, henceforth, cameras, applications, and more devices on these gadgets make it possible for students to be monitored while they write their examinations online. According to Atoum et al. (2017), automated Online Exam Proctoring allows for the availability of educational resources for students to write their examinations online without location restrictions. The study further found that automated proctoring remains effective, accurate, and efficient in carrying out examinations. Although students showed positive attitudes to OPE, several impending technical challenges still impede the effective implementation of OPE (lgaz \& Adanır, 2020).

\subsection{OPE; challenges and prospects during and after Covid-19}

Different government and privately-owned universities across the world that can afford the cost of OPE have been taking advantage of it during the Covid-19 pandemic. Since Covid-19 came unexpectedly, it was difficult to make schooling continue at the beginning of the pandemic as all business sectors needed to shut down. However, schools have since moved online and the use of OPE for learning assessment has increased. One of the major challenges of OPE is the fact that students in remote areas always find it difficult to have access to the internet; also in countries like India, China, and Nigeria where poverty is prevailing, there is a difficulty for learners to have access to devices like tablets, computers, etc. which could enable them to participate in OPE (Alderson, 2015; National Council for the Financing of Higher Education, 2020; Hastap Report About Global Self-Paced E-Learning Market, 2020).

In a study by Hastap Report About Global Self-Paced E-Learning Market 2020-2026 (2020), it was further revealed that after Covid-19, OPE would be of great use for universities that can implement it. Additionally, OPE will contribute largely to current digital growth in the education system- such that standardized examinations such as GRE, GMAT, TOEFL, AIMA MAT, and NLAT could continually be written through this system. According to Kubiatko (2020), one of the basic questions on the mind of professionals is if universities that have not been previously familiar with eLearning, and not at all with OPE, can maintain its use for at least a decade. It was further noted that though e-learning has great prospects such as OPE, future curricula, classic education, increasing virtual instructions, and many more; findings from India and Romania during Covid-19 have found that out of the $87 \%$ of universities' students who participated in e-learning and online assessment (OPE), about $42 \%$ of them could only use smartphones and not laptops. Some laptops were found to be owned by their parents, relatives, and friends (Kubiatko, 2020).

This, therefore, means that for e-learning, as well as OPE, to become effective across the world, students need to get sophisticated gadgets that will enable them to participate correctly in this process. According to Berkey and Halfond (2015), D'Souza and Siegfeldt (2017), OPE encourages weak personal ties among students, which could make them cheat in an open book examination. Although OPE lacks a strong classroom presence, a deep connection between students and teachers, and a 
fair learning environment, it could still be used efficiently. Kubiatko (2020) asserted that universities should take up the challenge of making eLearning as well as OPE viable in their institution through deliberate efforts. It was also added that computerbased assessments (OPE) have greater advantages over traditional paper-based examinations in all forms, such that audio, visual, audio-visual, animations, and more assessment characters are best put into use. Therefore, in a shift to align with global digital development and necessities, it is the role of universities to embrace the new norm and be globally relevant for quality assessment.

\section{Technical architecture and flow of OPE system}

Online Proctoring, designed to improve the validity of the remote exam process, offers a digital footprint to monitor the remote exam process. We provide a proctoring environment embedded within the homegrown university management system, the Safe Exam Browser (Halbherr et al., 2014, Lüthi et al., 2019), and Web RealTime Communication (WebRTC) based video proctoring (Fig. 1).

The Safe Exam Browser locks down the examination computer and prevents users from opening other browsers and prevents other applications from running in the background. The safe exam browser communicates over the internet (or a LAN) with the assessment module of the university management system running on a server. Additionally, the software disables the copy and paste features to help with integrity.

Exams may be taken on multiple devices such as computers, laptops, or mobiles, with the front-facing web camera mandatory for proctored exams and used for both authentication and monitoring students. A second side-facing camera from the mobile can be used to further monitor the student and the student's view of the computer screen. The system uses screen share, as well as unidirectional streaming for faculty to remotely monitor students during exams. The

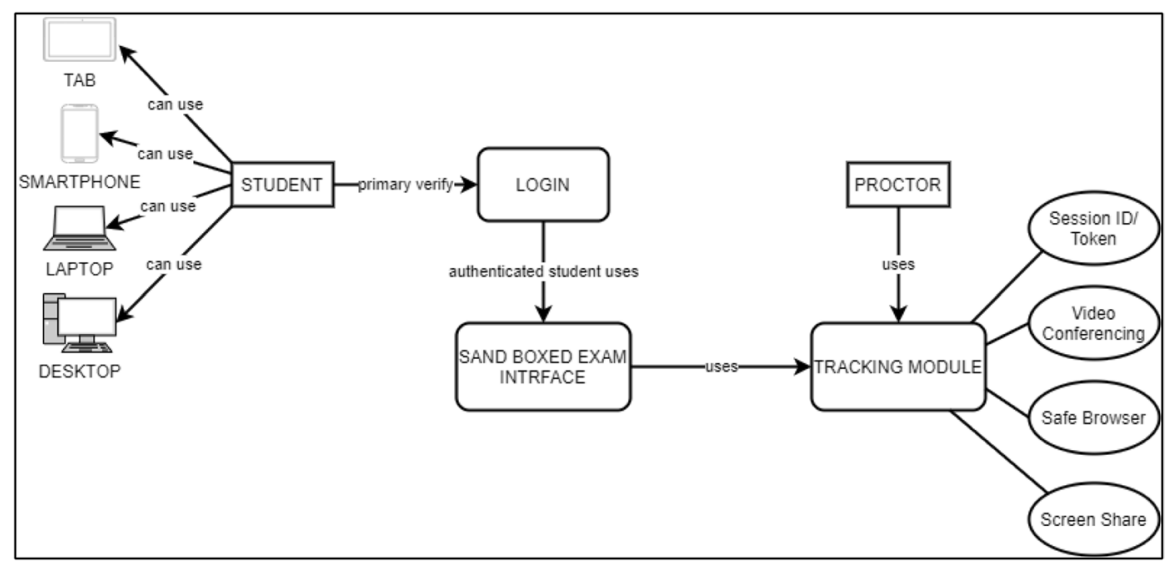

Fig. 1 High-level architecture and flow for online proctored exams 
MediaStream API of WebRTC transfers encrypted audio and video streams. Students show their ID cards to the camera and start the exam after verification. Audio proctoring is used to track possible voice-based cheating. A prerequisite for any proctored exam is to maintain academic integrity. Students verify their identity, and once authenticated, take the exams through the online exam interface. The tracking module tracks and records the entire exam. The exam sessions can be recorded and later analyzed to check for any violation.

The current method uses live online proctoring, where a trained human proctor monitors multiple students on a screen (Fig. 2). The two-way chat between the student and the online proctor is supported. If any violations are reported, the exam session locks, and students cannot continue the exam unless the invigilator manually updates the exam. Live chats are available to support the students for both technical support and monitoring.

The proctoring environment of the university management system is scalable and robust. During the period March 2020 to December 2020, nine schools of the university conducted semester exams online. Over 10,0000 students took their exams online. On an average 210 students were concurrently taking online exams. Other than the intermittent internet connection issues at the student end due to low bandwidth at remote areas, the system performed well. Based on the number of concurrent users, the performance and system reliability can be scaled by adding multiple computing nodes. Additionally, in-built load balancing allows an even distribution across nodes. Finally, all actions of the user are logged based on IP address.

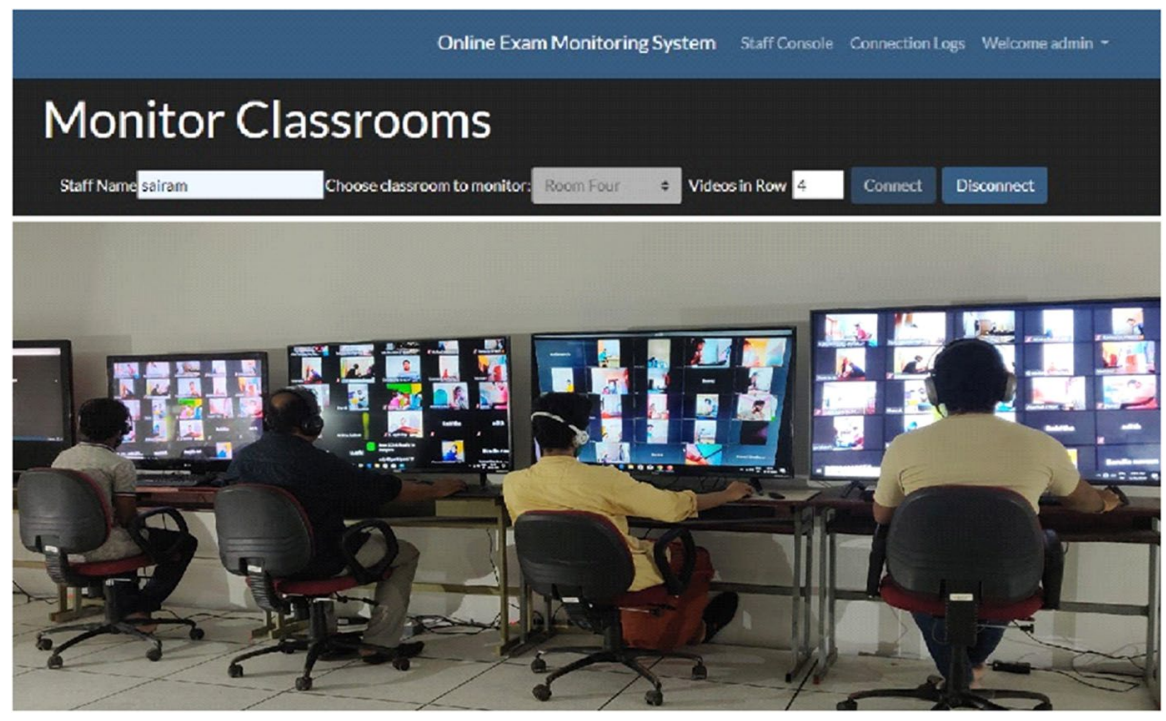

Fig. 2 Trained human proctors monitoring students taking online exams 


\section{Research model-Online Proctored Exams (OPE) as an innovation}

Educational innovation can come in various forms, such as e-learning, online exams, changes in curriculum, course, curricular and co-curricular reforms; departmental restructuring; the establishment of new revenue-generating programs; and overhauling outdated academic structures. Educational innovation diffusion studies have considered experiential learning (Raman et al., 2020), virtual labs (Achuthan et al., 2020), and students' evaluation of teaching (Raman \& Nedungadi, 2020).

According to Technology Acceptance Model (TAM) proposed by Davis (1989), perceived ease of use and perceived usefulness are two main innovation characteristics that affect an individual's behavioral intention to use the technology. Though TAM has been validated by empirical studies but because of its narrow focus on innovation characteristics namely perceived ease of use and perceived usefulness, the model is considered somewhat limiting (Awa et al., 2012). Another technology acceptance model is unified theory of acceptance and use of technology (UTAUT) (Venkatesh et al., 2003). It is to be noted that UTUAT is developed by integrating theories like Theory of Reasoned Action (TRA), the Technology Acceptance Model (TAM), Theory of Planned Behavior (TPB), Diffusion of Innovation Theory (DOI) etc. (Williams et al., 2011).

After carefully reviewing both TAM and UTUAT models, we focused on Rogers' Diffusion of Innovation Theory (DOI) which accommodates broader innovation characteristics such as the compatibility, observability, trialability of an innovation.

Rogers (2003) in his perceived theory of attributes writes that: 'the perceived attributes of innovation are one important explanation of the rate of adoption of an innovation. The theory states that an innovation is perceived based on its relative advantage, compatibility, complexity, trialability, and observability. For an innovation to undergo a faster rate of diffusion, the potential adopters must perceive that the innovation 1) has an advantage relative to other innovations 2) is compatible with existing practices and values 3 ) is not very complex 4) can be tried on a limited basis before adoption 5) offers observable results.

The survey consisted of five independent research variables hypothesized to be factors affecting the adoption of OPE namely-Relative Advantage, Compatibility, Ease of Use, Observability, Trialability (Fig. 3.)

Relative Advantage Rogers (2003) defines relative advantage as __ 'the degree to which an innovation is perceived as being better than the idea that it supersedes'. Here the focus is on the potential adopter and his perception of advantages of the innovation and not so much on the advantages proposed by the producer. We hypothesize that the Relative Advantage of Online Proctored Exams positively affects students' intention to adopt them.

Compatibility Rogers (2003) defines compatibility as _ the degree to which an innovation is perceived as consistent with existing values, past experiences, and needs of potential adopters. In terms of compatibility, is OPE methodology compatible in its functionality with the physical classroom exam method. OPE allows 


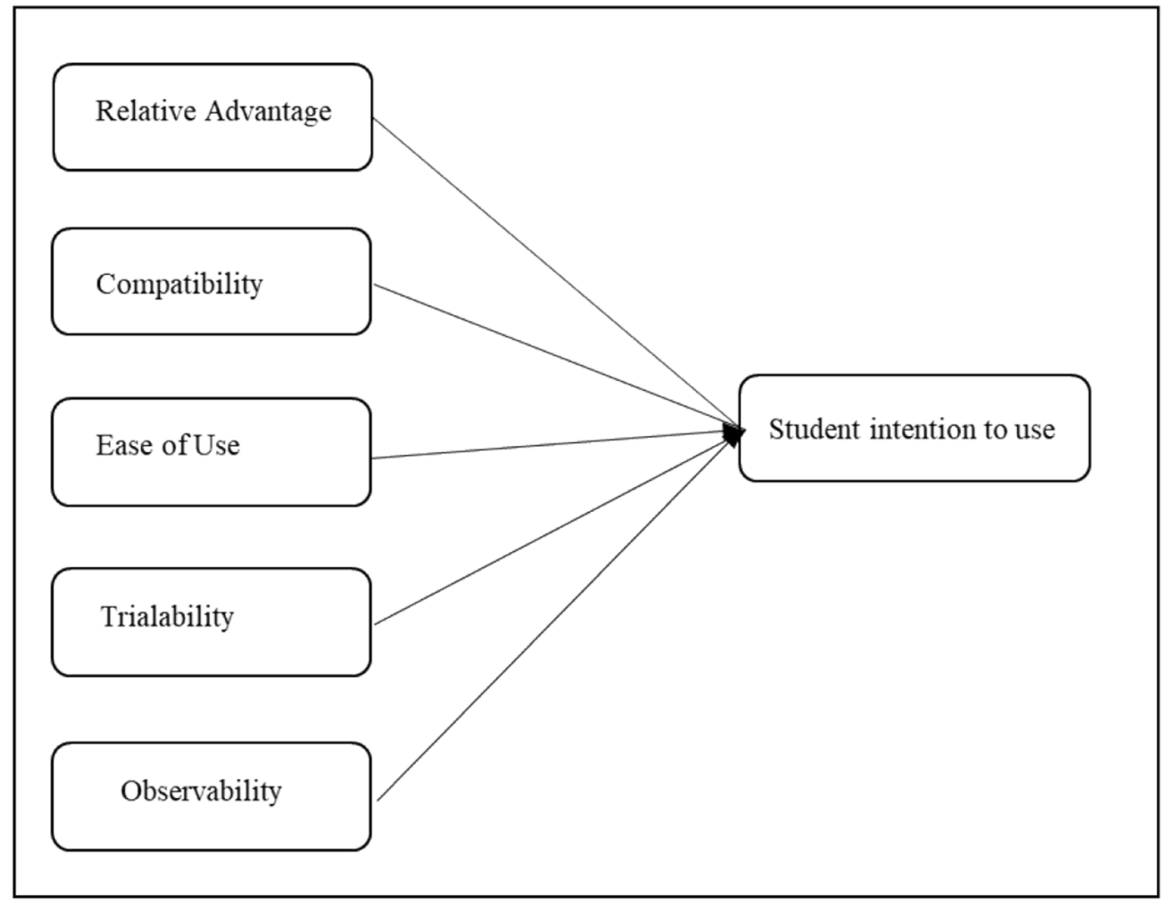

Fig. 3 Research model for student intentions to use OPE

for taking exams from the convenience of home and time yet the students are continuously monitored by human proctors very much like the physical classroom exam method. We hypothesize that the Compatibility of Online Proctored Exams positively affects students' intention to adopt them.

Complexity/Ease of Use Any innovation quickly gains a reputation as to its ease or difficulty of use (Rogers, 2003). Regarding complexity, an important question is to what extent OPE is perceived by students as complicated to use. New technologies that are simpler to use with less training are obviously adopted faster but more importantly learned more easily than more complex software. In specific, the idea of complexity, as described by Rogers' (2003), was formulated from an "Ease of use" perspective in this study whereas the notion of adoption was substituted with the notion of attitude towards use. We hypothesize that the Complexity of Online Proctored Exams negatively affects students' intention to adopt them.

Trialability Trialability is "the degree to which an innovation may be experimented with on a limited basis" (Rogers, 2003). Innovations like OPE that students can try out are more easily adopted because an innovation that can be tried presents less risk to the potential adopter. If there exists a way and opportunity to try an innovation and acquire personal experiences, it will notably decrease student apprehensions 
towards that innovation. We hypothesize that the Trialability of Online Proctored Exams positively affects students' intention to adopt them.

Observability Another aspect of innovation is the degree to which the results of an innovation are visible to others (Rogers, 2003). If potential adopters can see the benefits of an innovation, they will easily adopt it. We hypothesize that the Observability of Online Proctored Exams positively affects students' intention to adopt them.

Constructs from the diffusion model (Raman et al., 2020), virtual labs (Achuthan et al., 2020) guided both the selection and modification of questions from previously validated surveys, as well as the creation of new questions. Likert-scale questions were utilized throughout the questionnaire; the scale ranged from 1 to 5 , with 1 being strongly disagree and 5 being strongly agree. With inputs from faculty members and MIS team who developed the OPE software, pre survey feedback was designed and given to five students ( 2 males and 3 females) who had undergone OPE. A total of 33 questions were given to them and discussions with them were held to ensure that the questions were unambiguous and more importantly pertinent to their experiences about OPE. The total count of questions was reduced to 25 after this initial pre-survey study and was administered to 430 students to predict factors affecting students' intention to use OPE. The discussion begins with the frequency distribution of the participants.

Participation in the survey was entirely voluntary and students were told that the survey will be administered anonymously only after the final grades were announced.

The questionnaire was divided into two parts: (1) innovation construct questions (2) demographics section (characteristics of adopters) including gender, discipline, and level of study (undergraduate and graduate).

From the sample of 430 survey respondents, we observed that $114(26.5 \%)$ male and $316(73.5 \%)$ female students participated in the survey. Among these students, $99(23 \%)$ were from the Business program, 326 (75.8\%) Biotechnology, and 4 $(0.9 \%)$ students from Microbiology. Education-wise, 161 (37.4\%) were undergraduate students, whereas $269(62.6 \%)$ were postgraduate students.

\section{Discussion}

\subsection{Convergent validity and reliability}

Tables 1 and 2 provide details about convergent validity and reliability. The Kaiser-Meyer-Olkin (KMO) and Bartlett's test of sphericity are the measures of sampling adequacy. The KMO score greater than 0.5 is standard and nearer to 1 is superior. Bartlett's test of sphericity exhibits validity and relevance of the responses, which are gathered during the survey and must be lower than 0.05. Results of this study show that the KMO score is 0.9 and Bartlett's test is 0 . Therefore, the minimal threshold for sampling adequacy has been met. After ensuring sampling adequacy, 
Table 1 Reliability and validity

\begin{tabular}{llll}
\hline Constructs & Cronbach Alpha & AVE & CR \\
\hline Relative Advantage & 0.90 & 0.51 & 0.89 \\
Compatibility & 0.84 & 0.69 & 0.87 \\
Ease of Use & 0.87 & 0.58 & 0.89 \\
Trialability & 0.86 & 0.50 & 0.74 \\
Observability & 0.78 & 0.46 & 0.71 \\
Intention to Use & 0.75 & 0.60 & 0.85 \\
\hline
\end{tabular}

Scale $\alpha=0.91$

Table 2 Rotated component matrix $^{\mathrm{a}}$

\begin{tabular}{|c|c|c|c|c|c|c|}
\hline & 1 & 2 & 3 & 4 & 5 & 6 \\
\hline RA1 & 0.550 & & & & & \\
\hline RA2 & 0.796 & & & & & \\
\hline RA3 & 0.704 & & & & & \\
\hline RA4 & 0.774 & & & & & \\
\hline RA5 & 0.808 & & & & & \\
\hline RA6 & 0.781 & & & & & \\
\hline RA7 & 0.729 & & & & & \\
\hline RA8 & 0.663 & & & & & \\
\hline RA9 & 0.524 & & & & & \\
\hline $\mathrm{C} 1$ & & & & & 0.858 & \\
\hline $\mathrm{C} 2$ & & & & & 0.823 & \\
\hline C3 & & & & & 0.818 & \\
\hline EU1 & & 0.835 & & & & \\
\hline EU2 & & 0.828 & & & & \\
\hline EU3 & & 0.763 & & & & \\
\hline EU4 & & 0.547 & & & & \\
\hline EU5 & & 0.811 & & & & \\
\hline EU6 & & 0.777 & & & & \\
\hline $\mathrm{T} 1$ & & & & 0.724 & & \\
\hline $\mathrm{T} 2$ & & & & 0.720 & & \\
\hline $\mathrm{T} 3$ & & & & 0.660 & & \\
\hline $\mathrm{O} 1$ & & & 0.829 & & & \\
\hline $\mathrm{O} 2$ & & & 0.792 & & & \\
\hline $\mathrm{O} 3$ & & & 0.786 & & & \\
\hline $\mathrm{O} 4$ & & & 0.695 & & & \\
\hline IU1 & & & & & & 0.477 \\
\hline IU2 & & & & & & 0.823 \\
\hline IU3 & & & & & & 0.688 \\
\hline
\end{tabular}


KMO, and Bartlett's test of sphericity, we conducted factor analysis through exploratory factor analysis in SPSS 23. Factor loadings are between $0.477-0.855$, Cronbach alpha $(\alpha) 0.75-0.90$, composite reliability (CR) $0.71-0.89$, and average variance extracted (AVE) $0.46-0.69$. The minimum acceptable range for factor loading is 0.4. Similarly, the minimum acceptable value for AVE is 0.5 however, as low as 0.4 is also acceptable if the corresponding CR exceeds 0.6 (Hair et al., 2010).

In this study, the AVE of Observability is $0.46<0.5$ however, the corresponding CR exceeds 0.6 therefore, we can accept it for further analysis. Furthermore, minimum thresholds for $\alpha$ and CR is 0.5 that in our case has been achieved. Tables 1 and 2 indicate that all the measurement variables are within the acceptable statistical ranges (Hair et al., 2010). The discriminant validity is examined using Fornell and Larcker's (1981) criteria. It is obtained by comparing the square roots of each AVE value with absolute correlation coefficients of the latent variables. As shown in Table 3, the minimum value of the AVE square root is still higher than the maximum value of correlation coefficients. Thus, the condition of discriminant validity is also satisfied. According to Hair et al. (2010), these scores fulfill the minimum criteria for model fitness.

\subsection{Hypotheses testing}

For testing the hypotheses, we ran multiple regression analysis. The regression analysis has two basic assumptions: normality and multicollinearity. First, we examined the data for normal distribution skewness and kurtosis lie in between +1 and -1 also twice of the standard error is smaller than the statistic of the skewness, which confirms normality of the data. For multicollinearity, we examined tolerance level and variance inflation factor (VIF). Tolerance is below 0.87 and VIF is below 1.86, therefore, the threat of multicollinearity is also minimal. Tolerance and VIF scores have been reported in Table 4 and model summary in Table 5.

After confirming normal distribution and examining multicollinearity, we ran multiple regression to examine the hypotheses. Model summary (Table 5) suggests that the model explains $37.6 \%$ variance. Table 6 (multiple regression) exhibits that Relative Advantage $(\beta=0.24, p=0.00)$, Compatibility $(\beta=0.20, p=0.00)$, Ease Use $(\beta=0.22, p=0.00)$, Trialability $(\beta=0.14, p=0.00)$, and Observability $(\beta=0.08$,

Table 3 Discriminant validity

\begin{tabular}{lllllllll}
\hline Constructs & Mean & SD & 1 & 2 & 3 & 4 & 5 & 6 \\
\hline Relative Advantage & 3.16 & 0.81 & 0.71 & & & & & \\
Compatibility & 3.13 & 0.96 & 0.28 & 0.83 & & & & \\
Ease of Use & 3.36 & 0.83 & 0.30 & 0.12 & 0.76 & & & \\
Trialability & 3.15 & 0.90 & 0.65 & 0.25 & 0.28 & 0.70 & & \\
Observability & 3.18 & 0.81 & 0.19 & 0.37 & 0.32 & 0.12 & 0.67 & 0.77 \\
Intention to Use & 3.57 & 0.76 & 0.48 & 0.37 & 0.39 & 0.43 & 0.30 & \\
\hline
\end{tabular}


Table 4 Multiple regression

\begin{tabular}{lllllll}
\hline & $\beta$ & $\mathrm{SE}$ & $\mathrm{t}$ & $\mathrm{p}$ & Tolerance & $\mathrm{VIF}$ \\
\hline (Constant) & 0.977 & 0.171 & 5.716 & 0.00 & & \\
Relative Advantage & 0.249 & 0.050 & 4.756 & 0.00 & 0.537 & 1.86 \\
Compatibility & 0.208 & 0.034 & 4.855 & 0.00 & 0.816 & 1.22 \\
Ease of use & 0.226 & 0.039 & 5.325 & 0.00 & 0.833 & 1.20 \\
Trialability & 0.142 & 0.044 & 2.757 & 0.00 & 0.870 & 1.15 \\
Observability & 0.085 & 0.041 & 1.948 & 0.05 & 0.782 & 1.27 \\
\hline
\end{tabular}

Table 5 Model summary

\begin{tabular}{lllll}
\hline Model & $\mathrm{R}$ & R Square & Adjusted R Square & Std. Error of the Estimate \\
\hline 1 & $0.613^{\mathrm{a}}$ & 0.376 & 0.369 & 0.61014 \\
\hline
\end{tabular}

a. Predictors: (Constant), Observability, Trialability, Ease of Use, Compatibility, Relative Advantage

Table 6 Patterns for feature extraction

\begin{tabular}{ll}
\hline Feature & Pattern \\
\hline F1 & JJ NN NNS \\
F2 & NN NN+ \\
F3 & VBN/VBD NN NNS \\
F4 & JJ RB/RBR/RBS NN/NNS \\
F5 & RB/RBR/RBS JJ NN/NNS \\
\hline
\end{tabular}

$\mathrm{p}=0.00)$ are significant predictors of User's intention. Hence, all the assumptions are accepted (Fig. 4).

\subsection{Sentiment analysis}

Sentiment analysis is a set of tools in text analysis aimed at finding an opinion that highlights the positive or negative polarity about a particular process. Here, we mainly focus on the student's opinion about the new proctored examinations introduced at the University. Every student has some kind of opinion or attitude towards the new examination process. If we collect and analyze a lot of such feedback, we will get an overall picture of students' attitude towards such innovative methods conducting the examinations. In our study, we focused on Aspect Based Sentiment Analysis ABSA (Pontiki et al., 2016) where we identify which aspects or features students mention in feedback. For example, the feedback "Online monitoring was difficult for students with poor internet connectivity", ABSA would determine negative polarity towards internet connection. The task ABSA in a particular domain can be subdivided into the sub-tasks of aspect extraction, aspect category detection, and aspect polar checking. We used an unsupervised rule-based approach for aspect 


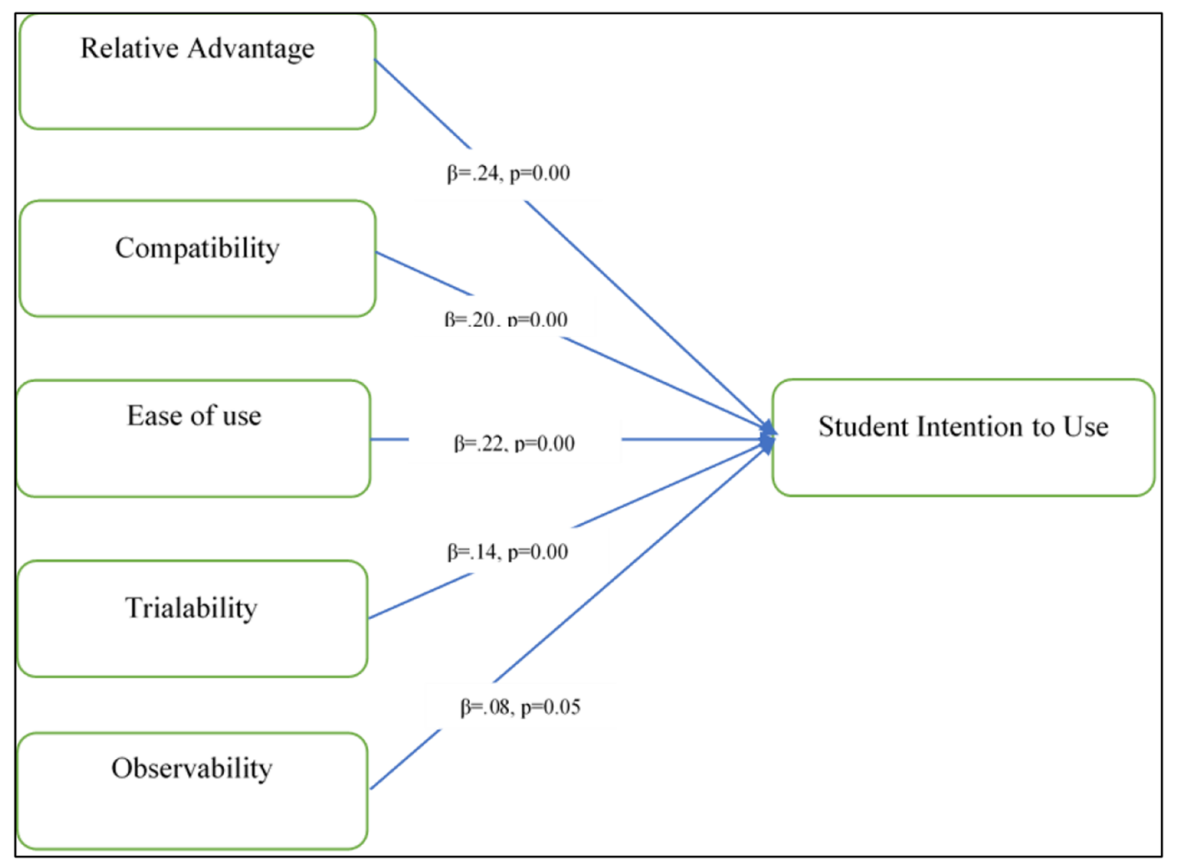

Fig. 4 Research model hypothesis testing

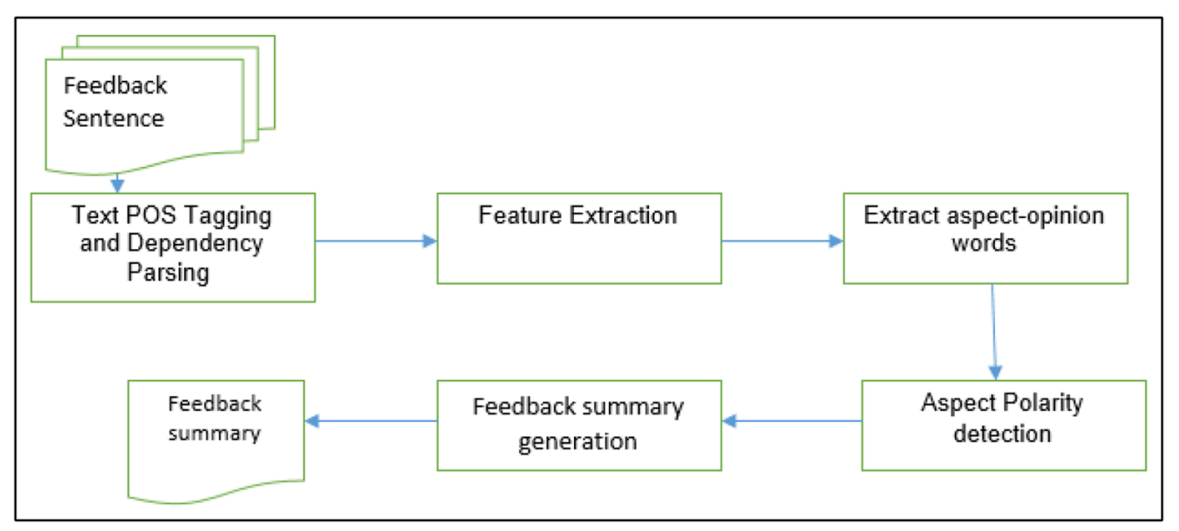

Fig. 5 Proposed method for aspect classification

extraction and polarity checking. Figure 5 shows the various modules present in this system. We have collected student feedback and grammatical tagging in the first phase. In this phase, each word present in the feed is labeled using a POS tagger. We have used the Stanford POS tagger (Toutanova et al., 2003). To find the aspect terms, syntactical relations are extracted using a dependency parser. (de Marneffe \& Manning, 2008). 


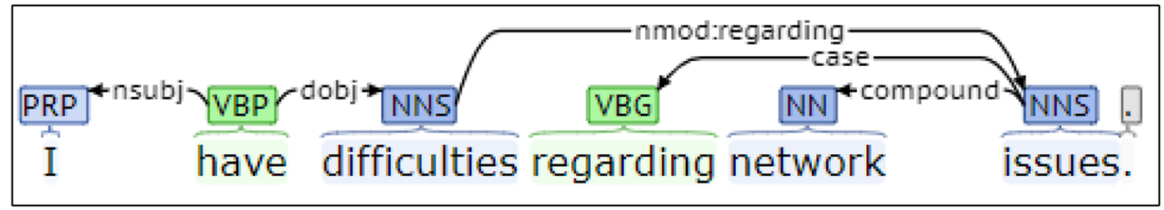

Fig. 6 Output of stanford dependency parser

Figure 6 shows the dependency relations between words in the sentence "I have difficulties regarding network issues". A set of handcrafted rules are used to extract the features present in the feedback. For example, a noun phrase preceded by an adjective is considered as feature F1.

We have used an unsupervised rule-based approach for extracting the opinion and features. For our study, we have created a small corpus of 1000 sentences extracted from the student feedback collected. VADER sentiment analyzer (Hutto \& Gilbert, 2014) is used for polarity checking. This sentiment analyzer does not make use of any training data set and each sentence of the feedback is rated as positive, negative, or neutral. Table 6 shows some of the patterns we have used for feature extraction. From these features, we next extracted opinion words and aspects. Usually, adverbs and adjectives are considered opinion words. Also, Bing Liu lexicon dictionary (Liu, 2012) is used to cross-verify the opinion words. The remaining phrases are considered as aspects. The polarity of the extracted phrases is checked using the VADER sentiment analyzer.

We also extracted the aspect phrases present in the feedback. We analyzed this list and identified the students' opinions towards OPE. We identified negative aspect terms such as "'net issues","poor internet connection","unstable network", "many problems" "frequent disconnection" etc. Also, the positive aspect terms were "sincere thanks", "very good experience", "strongly recommend","Good Job", "best way" etc. Our feedback ratios are $55.5 \%$ positive, $23.6 \%$ negative and $20.9 \%$ neutral. Evaluation of the result shows that our model achieves an accuracy of $78 \%$.

\section{Conclusions}

Several education providers were reluctant adopters of online learning and examination during the COVID pandemic. Online learning or OPE was not their first choice. This could be because of their unique business model where face-to-face providers believed that their key competitive advantage was their ability to deliver teaching and learning, as well as examinations on campus and that students choose them for this reason. Skepticism for online examination also included potential integrity issues, subterranean ethics (Kitto \& Saltmarsh, 2007), risk of academic misconduct, and technological and pedagogical challenges associated with setting up online examinations. Literature has proven that students put almost the same amount of effort into online examination v/s classroom-based exams (Myyry \& Joutsenvirta, 2015). The jury is out on overall outcomes of online education v/s classroom-based 
education and more research is needed. Some studies outline that student outcomes in results had a variable correlation with their GPAs when they were assessed online vs. in class (Eurboonyanun et al., 2020).

Looking from a student's access and ease point of view, OPE approach is a clear winner. Several studies before COVID and during the COVID period have highlighted that students generally are adapting very well to the online examination environment.

Our empirical results show that the Diffusion of Innovation theory operationalized in this study was successful in predicting the adoption of Online Proctored Exams by students. Innovation characteristics as identified by Rogers (2003) such as Relative Advantage, Compatibility, Ease of Use, Trialability, and Observability were found to be positively related to acceptance of OPE.

In this study, we have used the fine-grained Aspect Level Sentiment Analysis to check the students' attitudes towards the Online Proctored Exams. We also used linguistic features to extract the aspect terms present in the feedback comments. The experimental result shows that more than $55 \%$ of students had a positive attitude towards OPE. Around 24 percent of students show a negative attitude due to a network problem. The remaining 21 percent had a neutral attitude.

Work is in progress to enhance the current OPE system to AI-based video and audio analytics to alert for cheating patterns, image recognition to avoid impersonation, multi-face detection, object detection, audio tracking, and alerts based on the suspicious behavior to automate proctoring.

Recent research by some national regulatory bodies like TEQSA of Australia also clearly indicates that students have adapted well to the online learning and assessment during the COVID 19 pandemic, although challenges remain to the OPEs. In the UK, the uptake of proctored exams has been limited as highlighted by a small study done by QAA in 2020. Last year, students at Australian National University launched a petition against the use of OPE claiming that it was a gross violation of their privacy. The issue was again highlighted in August 2020 when the universities of Sydney and Melbourne confirmed that they were investigating an alleged data breach at ProcterU, the OPE toll they were using. Several researchers have indicated that online exams are particularly suitable for formative assessments rather than the summative assessment of learning (Shraim, 2019).

Designing the assessment for OPEs also plays a key part in the success of OPEs. Assessments need to be valid, reliable, secure, and flexible. Designing such examination tools requires training of the academic staff. This may pose a challenge to some education providers, especially in developing countries. Along with this, we are seeing a kind of divide between those who are in favor of authentic assessments and those in positivist or STEM disciplines where exams have been a norm (Times Higher Education, 2021). Several national and international professional accreditation bodies have not accepted authentic assessments as alternatives to exams.

As the results of this study present, OPEs can be considered as a student-friendly tool. The more holistic and long-term impact of OPEs requires further research. Challenges related to data breaches remain widespread. During the course of this study, other questions were raised about other variables and their relationships with acceptance. Because teachers implement policy and educational leaders enforce the 
implementation, it is important to consider the impact of leadership on teachers and the educational system. Coordinating a national study on teacher adoption of OPE will be another good next step. Technology acceptance models such as the Technology Acceptance Model (TAM) or Unified Theory of Acceptance and Use of Technology (UTAUT) can also be used to predict student intentions to adopt an innovation like OPE.

\section{Appendix}

\section{Survey questionnaire}

\section{Relative advantage}

- My participation in Online Proctored Exams will help improve my online learning skills.

- Online Proctored Exams will lead to higher level of engagement in my courses.

- Having a proctor made me feel credible about the exams.

- Online Proctored Exams is more interesting than other assessment approaches I have taken in the past.

- Online Proctored Exams made taking exams a better experience.

- I had more fun taking exams because of Online Proctored Exams.

- Online Proctored Exams helped me to learn more about technology while also learning about courses.

- Being selected for Online Proctored Exams is a status symbol.

- I am usually the first to try out new innovations like Online Proctored Exams.

\section{Compatibility}

- Online Proctored Exams fits right into the way I like to take exams.

- Participating in Online Proctored Exams will improve the quality of work I do.

- I had no difficulty in being continuously monitored on the camera.

\section{Ease of use}

- Instructions about taking Online Proctored Exams were easy to understand.

- I had no difficulty understanding how to get around in Online Proctored Exams.

- My role in Online Proctored Exams is clear and understandable.

- Participation in Online Proctored Exams will require a lot of training.

- I had no difficulty understanding how Online Proctored Exams technically worked.

\section{Trialability}

- Being able to try out Online Proctored Exams was important in my decision to use it. 
- It is easy to drop out of Online Proctored Exams.

- I am more likely to use Online Proctored Exams because of being part of this initial test.

- I really will not lose much by trying Online Proctored Exams, even if I do not like it.

\section{Observability}

- Other students seemed interested in Online Proctored Exams when they saw me using it.

- My friends can tell that I know more about online exams since I have used Online Proctored Exams.

- I have seen others taking Online Proctored Exams.

- I am aware of the benefits of Online Proctored Exams.

- I will join Online Proctored Exams after seeing my friends using it.

\section{Any other comments}

\section{Declarations}

The authors did not receive support from any organization for the submitted work.

Conflicts of interest/Competing interests The authors have no relevant financial or non-financial interests to disclose.

\section{References}

Achuthan, K., et al. (2020). Innovation adoption and diffusion of virtual laboratories. International Journal of Online and Biomedical Engineering (IJOE), 16(09), 4. https://doi.org/10.3991/ijoe.v16i09. 11685.

Alderson, J. (2015). The developing market for online proctoring. http://www.eduventures.com/2015/08/ the-developing-market-for-online-proctoring/.

Alessio, H. M., et al. (2017). Examining the effect of proctoring on online test scores. Online Learning, 21(1). https://doi.org/10.24059/olj.v21i1.885.

Amigud, A., et al. (2017). Using learning analytics for preserving academic integrity. The International Review of Research in Open and Distributed Learning, 18(5). https://doi.org/10.19173/irrodl.v18i5. 3103.

Atoum, Y., et al. (2017). Automated online exam proctoring. IEEE Transactions on Multimedia, 19(7), 1609-24.https://doi.org/10.1109/TMM.2017.2656064.

Awa, O. H., et al. (2012). Integrating TAM and TOE frameworks and expanding their characteristic constructs for e-commerce adoption by SMEs, 571-88. https://doi.org/10.28945/1676.

Berkey, D., \& Halfond, J. (2015). Cheating, student authentication and proctoring in online programs. New England Board of Higher Education, Summer 1-5. http://www.nebhe.org/thejournal/cheatingstudent-authentication-and-proctoring-in-online-programs/.

Corrigan-Gibbs, H., et al. (2015). Deterring cheating in online environments. ACM Transactions on Computer-Human Interaction, 22(6), 1-23. https://doi.org/10.1145/2810239.

Davis, F. D. (1989). Perceived usefulness, perceived ease of use, and user acceptance of information technology. MIS Quarterly, 13(3), 319. https://doi.org/10.2307/249008. 
Dawson, P. (2015). Five ways to hack and cheat with bring your own device electronic examinations. British Journal of Educational Technology, 12.

de Marneffe, M. -C., \& Manning, C. D. (2008). The Stanford Typed Dependencies Representation. Coling 2008: Proceedings of the Workshop on Cross-Framework and Cross-Domain Parser Evaluation - CrossParser '08, Association for Computational Linguistics, 1-8. https://doi.org/10.3115/1608858. 1608859.

D’Souza, K. A., \& Siegfeldt, D. V. (2017). A conceptual framework for detecting cheating in online and take-home exams: Conceptual framework for detecting cheating in exams. Decision Sciences Journal of Innovative Education, 15(4), 370-91. https://doi.org/10.1111/dsji.12140.

Eurboonyanun, C., et al. (2020). Adaptation to open-book online examination during the COVID-19 pandemic. Journal of Surgical Education, S1931720420303469. https://doi.org/10.1016/j.jsurg.2020. 08.046.

Fornell, C., \& Larcker, D. F. (1981). Structural equation models with unobservable variables and measurement error: Algebra and statistics. Journal of Marketing Research, 18, 382-388.

Hair, J. F., Black, W. C., Babin, B. J., \& Anderson, R. E. (2010). Multivariate data analysis (7th edn.). Prentice Hall.

Halbherr, T., et al. (2014). Making examinations more valid, meaningful and motivating: The online exams service at ETH Zurich. EUNIS Journal of Higher Education.

Hastap Report About Global Self-Paced E-Learning Market 2020-2026 (2020). Available online: https:// www.hashtap.com/@john.klok/global-self-paced-e-learning-market-2020-2026-businessplansma rket-size-industry-share-growth-manufacturers-and-outlook-with-fo-PxM4A1ZPLwbm.

Hovde, P., \& Olsen, U. (2015). Digital eksamen NTNU 2015-2019. 2015, NTNU: Trondheim, Norway.

Hutto, C. J. \& Gilbert, E. E. (2014). VADER: A parsimonious rule-based model for sentiment analysis of social media text. Eighth International Conference on Weblogs and Social Media (ICWSM-14). Ann Arbor, MI, June 2014.

lgaz, H., \& Adanır, G. A. (2020). Providing Online exams for online learners: Does it really matter for them? Education and Information Technologies, 25(2), 1255-69. https://doi.org/10.1007/ s10639-019-10020-6.

Kaiiali, M., et al. (2016). Designing a Secure Exam Management System (SEMS) for M-Learning Environments. IEEE Transactions on Learning Technologies, 9(3), 258-71. https://doi.org/10.1109/TLT. 2016.2524570

Kitto, S., \& Saltmarsh, S. (2007). The production of 'Proper Cheating' in online examinations within technological universities. International Journal of Qualitative Studies in Education, 20(2), 151-71. https://doi.org/10.1080/09518390600923792.

Kotsou, I., \& Leys, C. (2016). Self-Compassion Scale (SCS): Psychometric properties of the French translation and its relations with psychological well-being, affect and depression. PLoS One, edited by Philip Allen, 11(4), e0152880. https://doi.org/10.1371/journal.pone.0152880.

Kubiatko, M. (2020). Are ICT being used correctly? Small reflection about correct using of ICT in education. Problems Educ. 21st Century 2017, 75, 4-5.

Kyriazos, T. A. (2018a). Applied psychometrics: The 3-faced construct validation method, a routine for evaluating a factor structure. Psychology, 09(08), 2044-72. https://doi.org/10.4236/psych.2018. 98117.

Kyriazos, T. A. (2018b). Applied psychometrics: Sample size and sample power considerations in factor analysis (EFA, CFA) and SEM in General. Psychology, 09(08), 2207-30. https://doi.org/10.4236/ psych.2018.98126.

Liu, B. (2012). Sentiment analysis and opinion mining. In Synthesis lectures on human language technologies 5.1 (pp. 1-167).

Lüthi, T., Kern, M., et al. Competence-oriented exams using Virtual Desktop Infrastructure (VDI). Technical Report, 3rd Edition, Revised and Updated dalam https://www.safeexambrowser.org/about_ overview_en.html.

Manathunga, C. (2005). Early warning signs in postgraduate research education: A different approach to ensuring timely completions. Teaching in Higher Education, vol. 10(2), 219-33. https://doi.org/10. 1080/1356251042000337963.

Mohammad, H. (2015). Choice-based credit system in India: Pros and cons. Journal of Education and Practice, 6(25).

Myyry, L., \& Joutsenvirta, T. (2015). Open-book, open-web online examinations: Developing examination practices to support university students' learning and self-efficacy. Active Learning in Higher Education, 16(2), 119-32. https://doi.org/10.1177/1469787415574053. 
National Council for the Financing of Higher Education (2020). Report on The Number of Students in TheAcademic Year 2019-2020. Available online: http://www.cnfis.ro/wpcontent/uploads/2020/04/ SF_LMD1oct2019_preliminar_site.pdf. Accessed 23 June 2020.

Nie, D., et al. (2020). E-learning financing models in russia for sustainable development. Sustainability, 12(11), 4412. https://doi.org/10.3390/su12114412.

Northcutt, C. G., et al. (2016). Detecting and preventing 'multiple-account' cheating in massive open online courses. Computers \& Education, 100, 71-80. https://doi.org/10.1016/j.compedu.2016.04. 008 .

Patodkar, V. N., \& Sheikh, I.R. (2016). Twitter as a corpus for sentiment analysis and opinion mining. IJARCCE, 5(12), 320-22. https://doi.org/10.17148/IJARCCE.2016.51274.

Pontiki, M., et al. (2016). SemEval-2016 Task 5: Aspect based sentiment analysis. Proceedings of the 10th International Workshop on Semantic Evaluation (SemEval-2016), Association for Computational Linguistics, 19-30. https://doi.org/10.18653/v1/S16-1002.

Raman, R., et al. (2020). Investigating the factors affecting the adoption of experiential learning programs: MBA students experience with live-in-labs. 2020 IEEE Bangalore Humanitarian Technology Conference (B-HTC), IEEE, 1-6. https://doi.org/10.1109/B-HTC50970.2020.9297906.

Raman, R., \& Nedungadi, P. (2020). Adoption of Web-Enabled Student Evaluation of Teaching (WESET). International Journal of Emerging Technologies in Learning (IJET), 15(24), 191. https:// doi.org/10.3991/ijet.v15i24.17159.

Rogers, E. M. (2003). Diffusion of Innovations (5th ed.). Free Press.

Sindre, G., \& Vegendla, A. (2015). E-exams and exam process improvement, in UDIT 2015. Bibsys OJS:Ålesund. 13 .

Siemens, N. (2015). Toetsen op afstand (Online Proctoring): In een zaal met militaire precisie, op afstand, of gecombineerd?? https://www.surfspace.nl/artikel/1758-toetsen-opafstand-online-proctoring-ineen-zaalmet-militaire-precisie-op-afstand-ofgecombineerd/.

Shraim, K. (2019). Online examination practices in higher education institutions: Learners' perspectives. Turkish Online Journal of Distance Education, 185-96. https://doi.org/10.17718/tojde.640588. https://www.teqsa.gov.au/latest-news/articles/new-teqsa-report-details-student-experiences-switchonline-learning.

Sunar, A. S., et al. (2015). Personalisation of MOOCs - The State of the Art: Proceedings of the 7th International Conference on Computer Supported Education, SCITEPRESS - Science and and Technology Publications, 88-97. https://doi.org/10.5220/0005445200880097.

Times Higher Education. (2021, January 28). Online exams: is technology or authentic assessment the answer? https://www.timeshighereducation.com/news/online-exams-technology-or-authentic-asses sment-theanswer.

Toutanova, K., et al. (2003). Feature-rich part-of-speech tagging with a cyclic dependency network. Proceedings of the 2003 Conference of the North American Chapter of the Association for Computational Linguistics on Human Language Technology - NAACL '03, vol. 1, Association for Computational Linguistics, 173-80.https://doi.org/10.3115/1073445.1073478.

VADER (n.d.). A Parsimonious Rule-based Model for Sentiment Analysis of Social Media Text. Eighth International Conference on Weblogs and Social Media.

Venkatesh, V., Morris, M. G., Davis, G. B., \& Davis, F. D. (2003). "User acceptance of information technology: Toward a unified view. MIS Quarterly, 27, 3.

Williams, M. D, et al. (2011). Is UTAUT really used or just cited for the sake of it? Systematic review of citations of UTAUT's originating article". Proceedings of the 9th European Conference on Information Systems, ECIS 231.

Zhang, L., et al. (2010). Extracting and ranking product features in opinion documents. Proceedings of the 23rd international conference on computational linguistics: Posters. Association for Computational Linguistics, 1462-70. https://doi.org/10.5555/1944566.1944733.

Publisher's note Springer Nature remains neutral with regard to jurisdictional claims in published maps and institutional affiliations. 


\section{Authors and Affiliations}

\section{Raghu Raman ${ }^{1}$ (D) Sairam $B^{2} \cdot$ Veena $G^{3} \cdot$ Hardik Vachharajani ${ }^{4}$. Prema Nedungadi ${ }^{3}$}

Sairam B

sairamb@am.amrita.edu

Veena $\mathrm{G}$

veenag@am.amrita.edu

Hardik Vachharajani

hardik.vachharajani@cihe.edu.au

Prema Nedungadi

prema@amrita.edu

1 Amrita CREATE, Amrita School of Engineering, Amritapuri, Amrita Vishwa Vidyapeetham, Kollam, Kerala, India

2 Amrita School of Engineering, Amritapuri, Amrita Vishwa Vidyapeetham, Kollam, Kerala, India

3 Department of Computer Sciences \& Engineering, Amrita School of Engineering, Amritapuri, Amrita Vishwa Vidyapeetham, Kollam, Kerala, India

4 Crown Institute of Higher Education, North Sydney, Australia 